\title{
EL IMPUESTO A LAS HERENCIAS COMO UNA INSTITUCIÓN DE JUSTICIA*
}

\author{
Francisco Saffie \\ Universidad Adolfo Ibáñez
}

\begin{abstract}
Resumen: Este artículo defiende el impuesto a las herencias respondiendo a ciertas críticas recientes. Para ello el argumento parte mostrando la necesidad e importancia de distinguir entre las justificaciones morales y políticas de una institución y su regulación. Luego, en términos exploratorios, se dan razones para justificar un impuesto a las herencias como institución de justicia. El artículo concluye mostrando que las críticas que se han hecho en Chile al impuesto a las
\end{abstract}

Francisco Saffie Gatica. Licenciado en Ciencias Jurídicas y Sociales, Universidad de Chile; Magister en Tributación, Facultad de Economía y Negocios, Universidad de Chile; Becario Conicyt, Orsas y del College of Humanities and Social Science del programa de doctorado en derecho de la Universidad de Edimburgo, Escocia. Profesor de Derecho, Universidad Adolfo Ibáñez. Dirección electrónica: francisco.saffie@uai.cl.

* Una versión preliminar de este artículo fue presentada en el seminario de investigación del Centro de Regulación y Competencia de la Facultad de Derecho de la Universidad de Chile. Agradezco a Santiago Montt la invitación y a todos quienes participaron en dicho seminario por sus comentarios. Agradezco especialmente los comentarios que recibí de Fernando Atria L. y Antonio Bascuñán R., y las sugerencias de dos árbitros anónimos que me permitieron clarificar parte de los argumentos aquí expuestos. Cualquier error es de mi exclusiva responsabilidad. 
herencias no ofrecen argumentos al nivel de los principios de justicia ni tampoco en el de la regulación vigente en el país. Al adolecer de estos problemas, las críticas contra el impuesto a las herencias son injustificadas e inaplicables a la regulación vigente.

Palabras clave: Impuesto a las herencias, justicia, propiedad privada, potestad de asignar, derecho a la herencia.

Recibido: mayo 2011; aceptado: abril 2012.

\section{INHERITANCE TAXATION AS AN INSTITUTION OF JUSTICE}

Abstract: This essay advocates for inheritance taxation and defends it from recent criticism. The first part of the argument shows the need and importance of distinguishing moral and political justifications from the regulation of an institution. Then, in exploratory terms, arguments to justify inheritance tax as an institution of justice are provided. The article concludes by showing that the criticism developed in Chile against the inheritance tax does not offer arguments neither in the level of principles of justice nor regarding the applicable statutes. Because of these problems, criticism against inheritance tax lacks justification and is inapplicable to Chilean valid law.

Keywords: inheritance taxation, justice, private property, power to allocate, right to inherit.

Received: May 2011; accepted: April 2012. 
Lo que mediante el dinero es para mí, lo que puedo pagar, es decir, lo que el dinero puede comprar, eso soy yo, el poseedor del dinero mismo. Mi fuerza es tan grande como lo sea la fuerza del dinero. Las cualidades del dinero son mis - de su poseedor - cualidades y fuerzas esenciales. Lo que soy yo y lo que puedo no están determinados en modo alguno por mi individualidad. [...] ¿Acaso no transforma mi dinero todas mis carencias en su contrario? (K. Marx, "El poder del dinero", Tercer Manuscrito, en Manuscritos Económicos y Filosóficos, 1844.)

Veo perfectamente lo que os impresiona: en vuestro concepto, la herencia sólo sirve para mantener la desigualdad; pero ésta no procede de la herencia, sino que resulta

de los conflictos económicos. La herencia toma las cosas como las encuentra: cread la igualdad, y la herencia la sostendrá siempre. [...] Lo que le falta al pobre no es la herencia (el derecho de heredar), sino el patrimonio.

(P. J. Proudhon, Sistema de las Contradicciones Económicas o Filosofía de la Miseria, 1846.)

A nadie podría extrañar si un diagnóstico de la actividad de filósofos políticos y morales mostrara que para ellos el diseño de las instituciones fiscales ha sido abandonado como un problema relevante, y que el diseño y justificación de estas instituciones ha sido dejado a economistas liberales que entienden los tributos como un mecanismo orientado a la obtención de ingresos fiscales teniendo en consideración sus efectos en el funcionamiento de la economía. Así por ejemplo en Chile, la política tributaria no ha cambiado substantivamente desde que en 'El Ladrillo' se estableciera que los “objetivos fundamentales" de la política tributaria son: (i) contribuir a una asignación eficiente de recursos desde una perspectiva social, (ii) obtener recursos necesarios para cubrir el gasto fiscal, y (iii) contribuir a una mejor distribución del ingreso ${ }^{1}$, sin que nada se dijera respecto de la justificación de estos "objetivos fundamentales" mas que dar por sentada la necesidad de establecer un nuevo modelo económico. El diagnóstico empeoraría cuando un análisis detallado de las más recientes teorías de la justicia podría mostrar que éstas también asumen que la principal función de los tributos es obtener financiamiento para la realización de las actividades del Estado, v.gr. la distribución de un mínimo de bienes públicos

1 "El Ladrillo": Bases de la Política Económica del Gobierno Militar Chileno, 103. 
(como en el caso de teorías libertarias) o la asignación de ciertos bienes conforme al reconocimiento y realización de derechos sociales (en el caso de teorías que asignan una mayor actividad al Estado), descuidando la justificación no económica de estas instituciones. Esto ha llevado a que los tributos sean vistos de manera casi exclusiva como medios para la obtención de un fin (o de determinados efectos) y no como instituciones que encarnan concepciones de justicia. De esta forma, hemos olvidado que otro tipo de justificación subyace al diseño institucional fiscal. Un análisis de las consecuencias de esta comprensión de los tributos para una teoría general del derecho tributario excede con creces los objetivos de este trabajo. Sin embargo, un análisis particular del impuesto a las herencias ${ }^{2}$-últimamente fuertemente cuestionado en Chile - puede mostrar la relevancia que los argumentos de justicia política y moral tienen en la justificación de las instituciones fiscales. La elección del impuesto a la herencia como objeto de análisis no es antojadiza; no sólo porque muchos de los argumentos que se dan contra este impuesto son la base de una posible extensión en contra de los impuestos a la renta, sino también porque la idea que subyace a este impuesto es particularmente importante al momento de definir la forma en que nos relacionamos unos con otros como miembros de una comunidad política. En otras palabras, el impuesto a la herencia es una de aquellas instituciones fiscales en las que subyace una importante idea no económica de justicia que la justifica. Sin embargo, si hay algo que llama la atención respecto de la discusión sobre este impuesto en Chile es la forma en que argumentos de eficiencia y justicia se aplican al análisis de las reglas que regulan el impuesto a las herencias sin que se den argumentos de justicia que justifiquen esas críticas. Además, y lo que parece más grave, estas críticas no son siquiera aplicables a la regulación vigente en nuestro país.

Así, en lo que sigue, intentaré mostrar en su mejor versión los argumentos que se han esgrimido en Chile contra el impuesto a la herencia (I); argumentaré que para poder entender el problema de justicia tras

${ }^{2}$ En Chile el impuesto a las herencias está regulado en la Ley 16271, sobre impuesto a las herencias, asignaciones y donaciones. Para efectos de desarrollar el argumento de este trabajo, y como queda claro en el argumento del texto principal, en lo que sigue me refiero al impuesto a las herencias sin denotar a la regulación positiva del impuesto sino que a la idea de aplicar un impuesto a la riqueza heredada o transferida a título gratuito. Cuando me refiero a la regulación de la Ley 16271 así lo señalo en el cuerpo del texto. 
las críticas es necesario separar los niveles de análisis, entre el nivel de las reglas que regulan la institución y el de las razones de justicia que subyacen a la institución del impuesto a la herencia (y de los tributos en general) (II); daré algunas justificaciones para el impuesto a la herencia como elemento central de aquellas instituciones que hacen posible la vida en comunidad de manera acorde con una distribución adecuada de beneficios y obligaciones sociales entre ciudadanos (III); y, finalmente, mostraré cómo las críticas que se hacen al impuesto a la herencia en Chile son estériles e injustificadas (IV).

\section{El 'impuesto sin sentido'}

A modo de resumen, en esta sección presento los argumentos que en los últimos años se han esgrimido en Chile contra el impuesto a las herencias. Estos argumentos se han dado a conocer en distintos medios de prensa, mediante columnas de opinión en diarios y reportajes con opiniones de abogados, políticos y economistas ${ }^{3}$, y llegaron incluso a sostenerse por los candidatos presidenciales en los debates que antecedieron la última elección presidencial. El objetivo de estos argumentos es hacernos saber que existe unanimidad en cuanto a la injusticia e irrelevancia económica del impuesto a las herencias. Los argumentos son variados, pero en general se presentan de la siguiente forma:

a) El impuesto a las herencias es un impuesto patrimonial. En este punto se sostiene que es un impuesto que afecta a un patrimonio y como tal iría contra la regulación constitucional chilena, conforme

3 Véase a modo de ejemplo El Mercurio, Economía y Negocios de 14.05.07, 'Impuesto a la herencia golpea bolsillos de sectores medios'; 06.08.07, 'El impacto que el impuesto a la herencia tiene en las sucesiones'; y de 26.08.09, 'Distorsión y baja recaudación intensifican consenso para eliminar impuesto a la herencia'; los editoriales de 27.08.09, 'Un impuesto sin sentido'; y de 07.04.11, 'Rebajar el impuesto a la herencia'. También puede verse la columna de opinión 'Impuesto de herencia' de Paul Fontaine B., en el Diario Financiero de 13.11.09. Recientemente, como da cuenta el diario La Tercera de 02.04.11 (p. 48), los senadores Longueira y Tuma durante la discusión del presupuesto 2011 solicitaron al gobierno la eliminación del impuesto a la herencia por las razones aquí señaladas. Según esta misma información, el Ministerio de Hacienda encargó un estudio al Servicio de Impuestos Internos con miras a proponer una disminución de las tasas del impuesto. 
lo establecido en el inciso primero del artículo $19 \mathrm{~N}^{\mathrm{o}} 20$ de la constitución ${ }^{4}$.

b) El impuesto a las herencias grava dos veces el mismo patrimonio. Según este argumento, el impuesto a las herencias implica una doble tributación sobre un patrimonio que ha ido pagando impuestos a medida que se ha formado y que volvería a pagar impuestos una vez que fallece su titular. La posibilidad de sostener este argumento depende de que la regulación del impuesto conlleve una doble tributación.

c) Es un impuesto que atenta contra las familias. Aquí se sostiene que las familias se verían afectadas por dos razones: (i) serían objeto de discriminación porque se aplica un impuesto directamente a las transferencias entre familiares 5 ; $y$, (ii) muchas familias que desarrollan actividades económicas ven afectados sus negocios actuales y sus posibilidades de emprender nuevos negocios. En otras palabras, el impuesto a las herencias afecta de manera importante la viabilidad económica de las llamadas "empresas familiares".

d) Es un impuesto inequitativo en su aplicación porque en los hechos grava sólo a los "sectores medios y medios bajos" que son quienes efectivamente lo pagan. Este argumento parte del hecho que las familias con altos patrimonios han "planificado legalmente la herencia", en términos tales que al momento de fallecer una persona no existe patrimonio hereditario que distribuir (i.e., la base imponible sobre la que se determina el monto del impuesto), y por tanto no hay herencia que gravar con el impuesto.

e) Es un impuesto ineficiente porque recauda pocos ingresos para el Estado. Tradicionalmente se sostiene que el impuesto a las herencias representa un porcentaje marginal del total de los ingresos fiscales y que su fiscalización implica grandes costos, por lo que en términos económicos es un impuesto ineficiente que no se justifica ${ }^{6}$.

${ }^{4}$ En el artículo $19 \mathrm{~N}^{\mathrm{o}} 20$, inciso primero, la constitución asegura a todas las personas "la igual repartición de los tributos en proporción a las rentas o en la progresión o forma que fije la ley, y la igual repartición de las demás cargas públicas".

${ }^{5}$ Transferencia se utiliza aquí en un sentido amplio, distinto del técnico jurídico civil, para incluir transmisiones y transferencias a título gratuito.

${ }^{6}$ Junto con otros impuestos menores en recaudación el impuesto a las herencias representó en el año 2009 (última información disponible en la página web del Servicio de Impuestos Internos al momento de escribir este artículo) un $2,7 \%$ del total de los ingresos tributarios anuales. Los años anteriores, desde el año 1993, este porcentaje no superó el 1,6\% del total de los ingresos tributarios anuales. Lo que no deja de llamar la atención es que el año 2009 la recaudación subió porque según es de público conocimiento, ver las notas de la prensa referidas en n.3, la familia de Anacleto Angelini decidió pagar el impuesto. 
En definitiva se trataría de un impuesto "sin sentido" porque además de no recaudar recursos para el Estado "ataca" injustificadamente a las familias.

Estos argumentos no son exclusivos de nuestro país, como tampoco las consecuencias que de ellos derivan sus defensores. Un análisis de las discusiones que sobre este impuesto se han desarrollado en otras jurisdicciones muestra que se trata, en general, de argumentos importados desde países en los que se han iniciado abiertamente campañas para la eliminación del impuesto a las herencias. En Chile, en particular, existe una clara simpatía por replicar los argumentos desarrollados en Estados Unidos a partir de la segunda mitad de los años 70 y por el tipo de solución allí propuesta: o la eliminación del impuesto o elevar los montos exentos disminuyendo los tramos en los que se aplica el impuesto disminuyendo las tasas ${ }^{7}$. Una cuestión que se hará evidente hacia el final de este trabajo es que sin diferenciar los niveles de argumentación a los que se dirigen estos ataques, distinción que analizaré en la próxima sección, algunos de ellos son inaplicables a la regulación chilena y otros no responden a la concepción de justicia encarnada en nuestras instituciones.

${ }^{7}$ Véase la descripción de la evolución de los argumentos contra el equivalente al impuesto a las herencias en Estados Unidos (estate tax, que se aplica sobre la totalidad del patrimonio hereditario) en Graetz y Shapiro, Death by a Thousand Cuts: The Fight over Taxing Inherited Wealth. Según estos autores algunos de los argumentos dados en esa discusión eran abiertamente falsos y respondían a los intereses de los grupos que estaban detrás de una campaña contra el impuesto. Esto, me temo, es también lo que está ocurriendo en Chile.

En general, en el derecho comparado la regulación positiva de los impuestos a las herencias ha adoptado un esquema de tasas progresivas. Así ocurre por ejemplo en la regulación alemana, francesa y estadounidense (antes de la reforma del año 2001, en la que se estableció una disminución progresiva de la tasa del impuesto hasta llegar a cero el año 2010). Hoy se discute la posibilidad de establecer un impuesto a la herencia con una estructura similar a la del vigente en Chile. Véase, Batchelder, "What Should Society Expect from Heirs? A Proposal for a Comprehensive Inheritance Tax", 2009; "Taxing Privilege More Effectively: Replacing the Estate Tax with an Inheritance Tax", 2007; "Estate Tax Reforms: Issues and Options", 2009). En cambio, la regulación de la base imponible y de los obligados al pago son distintas. Así, en Alemania y Francia el impuesto se aplica sobre la asignación hereditaria, mientras que en Estados Unidos el impuesto se aplica sobre la totalidad del patrimonio hereditario. Para un interesante análisis sociológico sobre la evolución de la regulación legal de la herencia en Alemania, Estados Unidos y Francia, véase Beckert, Inherited Wealth. 
Los sistemas tributarios, entendiendo por ello el conjunto de instituciones fiscales que forman parte de la estructura de política económica de un determinado gobierno, tradicionalmente se han evaluado bajo criterios de justicia (económica) y eficiencia ${ }^{8}$. Estos criterios son, sin embargo, sólo relevantes una vez que tenemos una estructura institucional, la que se debe evaluar o contrastar bajo ciertos estándares o principios de justicia. Sin tener claridad respecto de cuáles son las demandas de justicia tras las instituciones se hace difícil siquiera entender algunas de las críticas aquí presentadas. En parte, el problema con estas críticas es que desconocen estos dos niveles de análisis y confunden demandas de justicia con ciertas consecuencias no deseadas que se derivan de una regulación particular pretendiendo obtener, de estas consecuencias, conclusiones a nivel de principios de justicia, en lugar de proponer modificaciones en el nivel regulatorio para subsanar esas deficiencias prácticas. Espero que esta afirmación quede más clara con el desarrollo del argumento en el apartado que sigue.

\section{Instituciones y justicia distributiva}

Desde que John Rawls intentó revivir la tradición contractualista en $A$ Theory of Justice $e^{9}$ la discusión acerca de la relación entre justicia distributiva e instituciones se volvió un tema central en la filosofía política contemporánea. ¿Cómo conseguir que las interacciones sociales sean justas? ¿Cómo distribuir de manera justa los derechos y deberes propios de la vida en sociedad? La respuesta de Rawls consistió en mostrar que para conseguir distribuciones justas es necesario aplicar los principios de justicia al diseño de la estructura básica de la sociedad. Estos principios de justicia, i.e. el principio de igual libertad y el principio de la diferencia, son aquellos que serían acordados por cualquier persona que actúa en un escenario hipotético ideal, tras un velo de ignorancia que asegura que en condiciones de igualdad inicial y teniendo en consideración las circunstancias de la justicia, un grupo de personas decidirá de manera definitiva los estándares que se aplicarán en sus fu-

${ }^{8}$ Por todos, Murphy y Nagel, The Myth of Ownership. Taxes and Justice, 2001, 12 .

${ }^{9}$ Rawls, A Theory of Justice, 1999. Digo intentó porque G. A. Cohen ha puesto en duda con buenos argumentos el carácter contractual de la teoría de Rawls. Véase Cohen, Rescuing Justice \& Equality, 2008, 337 y ss. 
turos acuerdos sociales. De esta forma, en un esquema de justicia puramente procesal regido por los principios de justicia, la distribución del producto social será siempre justa puesto que todas las personas tendrán igual acceso a las posiciones sociales de privilegio y las inevitables desigualdades sociales serán aceptables para todos porque mejorarán la situación de los menos aventajados ${ }^{10}$.

En este esquema, las instituciones — “aquellos sistemas públicos de reglas que definen cargos y posiciones con sus derechos y deberes, poderes e inmunidades"11_ que son parte de la estructura básica de la sociedad tienen un rol central, puesto que son la materialización de los principios de justicia de una sociedad y determinan en su operación la justicia substantiva. Con este argumento, Rawls pretendió acercar lo más posible la justicia formal y la justicia substantiva ${ }^{12}$.

La importancia de las instituciones en una teoría ética como el constructivismo rawlsiano es evidente ${ }^{13}$. Sin la particularización que supone un diseño de reglas, la abstracción y generalidad de los principios de justicia hace difícil determinar la forma en que nuestras conductas particulares se ajustan a las restricciones que impone la justicia. En términos de Onora O’Neill, “[i]nstituciones y prácticas justas proveen la especificación necesaria para juzgar la justicia de actos o decisiones particulares"14. Así, el diseño institucional debe ajustarse lo más posible a los principios de justicia de manera tal que el resultado conjunto de acciones individuales dentro del esquema deóntico definido por la(s) institución(es) sea justo.

Pero la importancia del diseño institucional no sólo es central para teorías constructivistas. Incluso para quienes se oponen a la idea de

${ }^{10}$ Asumo para efectos de este trabajo que no es necesario explicar cada uno de los conceptos propios de la teoría de la justicia de Rawls y que tampoco afecta al argumento principal la discusión detallada de algunos de sus elementos que se encuentran en la literatura sobre la materia. Para una descripción básica de estas ideas véase Rawls, A Theory of Justice, 1999, capítulo 1.

${ }^{11}$ Rawls, Teoría de la Justicia [1971], 1995), 62.

12 Ibíd., 67.

13 "El constructivismo político es un punto de vista acerca de la estructura y del contenido de una concepción política. Expresa que en cuanto se logra - si es que alguna vez se logra - el equilibrio reflexivo, los principios de la justicia política (el contenido) pueden presentarse como el resultado de cierto procedimiento de construcción (la estructura)", Liberalismo Político [1977], 1995) 101.

${ }^{14}$ O'Neill, Towards Justice and Virtue: A Constructive Account of Practical Reasoning, 1996, 182. (Traducción personal). 
que los principios de justicia puedan determinarse procedimentalmente $\mathrm{y}$, en consecuencia, sostienen que la determinación de estos principios es independiente de restricciones fácticas, como lo hace G. A. Cohen ${ }^{15}$, las reglas que forman parte de un acuerdo institucional son la única forma en que podemos actuar sin vernos enfrentados en cada una de nuestras decisiones al problema de reflexionar sobre los principios últimos de justicia ${ }^{16}$. En este caso, los principios de justicia son relevantes cada vez que debemos dejar atrás las reglas para determinar reflexivamente qué es lo justo, qué es aquello que la justicia demanda. Estas versiones de la relación entre justicia y reglas institucionales nos permiten separar lo que la justicia demanda de aquello que es posible en atención a las circunstancias de hecho que restringen la posibilidad de obtener (en nuestras sociedades imperfectas) distribuciones justas, sin afectar la defensa de una determinada concepción de justicia ${ }^{17}$.

Las dos teorías aquí especificadas para ejemplificar la forma en que las instituciones se vinculan con la justicia, son teorías de la justicia que se enmarcan dentro de lo que se ha llamado liberalismo rawlsiano e igualitarismo de suerte (entre los que se encuentra Cohen). Este tipo de teorías no busca determinar qué es la justicia distributiva o justicia social, pero parten del entendido que se trata de "la primera virtud de las instituciones sociales" 18 o "una virtud difícil de determinar sobre la que los filósofos han discutido por algunos pocos miles de años"19 que, partiendo del entendido de que los seres humanos merecen igual respeto, sólo aceptan desigualdades que puedan ser justificadas, i.e. a través del principio de la diferencia o cuando se trata del ingreso individual, por ejemplo, por las elecciones individuales entre ingreso y ocio, respectivamente ${ }^{20}$.

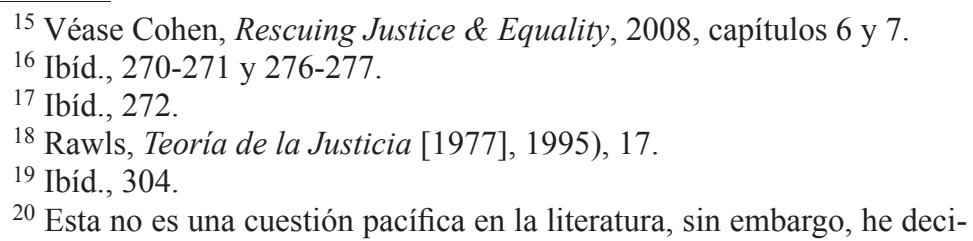
dido no discutir sobre la relación entre principios de justicia e instituciones con más detalle. Liam Murphy ha defendido de manera interesante, aunque a mi juicio sin éxito, lo que él denomina un monismo valorativo como demandas de justicia que se aplican con independencia de un esquema institucional. Véase Murphy, Moral Demands in Nonideal Theory, 2000; y del mismo, "Institutions and the Demands of Justice", 1998. 
Lo que me interesa rescatar de estas teorías de la justicia es el punto metodológico que entiende la importancia de distinguir y vincular en un nivel teórico dos niveles de análisis: el de los ideales de justicia y el de la necesidad de contar con regulaciones que permitan la operación de estos ideales de justicia. Ya sea que los ideales de justicia sean determinados procedimentalmente o a través de una comprensión moral de los mismos (o conforme recomiende otra teoría de la justicia), una vez que acordamos cuál es el contenido de estos ideales, necesitamos de arreglos institucionales que les den forma. En este nivel de análisis, la determinación específica de las reglas de la institución, i.e. la regulación de la institución, es una cuestión secundaria que dependerá de las características y necesidades particulares de una determinada comunidad política. Esta cuestión, si bien importante, no es determinante ni modifica aquello que es justo.

\section{Dotando de sentido al impuesto a las herencias}

En este apartado me gustaría mostrar cómo, ya sea adoptando el constructivismo rawlsiano o los principios de justicia insensibles a restricciones fácticas de Cohen, el impuesto a las herencias se vuelve necesario para acercarnos a la materialización de las demandas que supone la justicia distributiva.

Al momento de analizar las instituciones básicas de la sociedad que forman parte de la economía política ${ }^{21}$, Rawls parte su análisis dividiendo las actividades del Estado en cuatro ramas ${ }^{22}$. En lo que interesa para efectos de este artículo me concentraré en la rama de distribución, que es aquella que está directamente relacionada con los tributos. Esta rama tiene la "tarea de conservar una justicia aproximada de las porciones distributivas mediante la tributación y los reajustes a los derechos de propiedad" y para ello pueden distinguirse dos aspectos. Uno de estos aspectos es el de la tributación que busca "recabar los ingresos que

21 Siguiendo a Rawls, la economía política comprende el conjunto de "normas según las cuales evaluamos los esquemas económicos y los programas políticos", (Rawls, Teoría de la Justicia [1977], 1995) 243).

22 Ibíd., 258 y ss. Estas ramas son: la de asignación, la estabilizadora, la de transferencia y la de distribución. Más tarde Rawls agregará una quinta rama, la de cambio, que permite a los miembros de una sociedad justa determinar la dirección del gasto público en circunstancias excepcionales como si se tratara de un problema comercial. Ibíd., 264 y ss. 
requiere la justicia"23. El aspecto relevante para el análisis desarrollado en este artículo, es aquél que busca

corregir, gradual y continuamente, la distribución de riqueza y prevenir las concentraciones de poder perjudiciales para la equidad de la libertad política y de la justa igualdad de oportunidades ${ }^{24}$.

Recordemos que para Rawls sólo son aceptables aquellas desigualdades que satisfacen el principio de la diferencia, i.e. cuando las desigualdades sociales mejoran la situación de aquellos que están en situaciones menos aventajadas, una vez que se ha asegurado el respeto del primer principio de la justicia, i.e. igual derecho para cada persona a un esquema de libertades básicas compatible con un esquema semejante para los demás. En consecuencia, el estándar para evaluar las posibles desigualdades sociales supone que haya existido una situación inicial de igualdad de oportunidades. En este esquema han de corregirse todas aquellas desigualdades naturales y de origen que se alejan del ideal de igualdad inicial. Es así como Rawls reconoce en la herencia, natural o social, una de aquellas desigualdades que deben corregirse cuando afirma,

[r]ecibir por herencia una riqueza desigual no es más injusto, intrínsecamente, que recibir por herencia una inteligencia desigual. Así, la herencia es permisible, siempre que la desigualdad resultante vaya en ventaja de los menos afortunados y sea compatible con la libertad y la justa igualdad de oportunidades ${ }^{25}$.

Afortunadamente, para eliminar el primer tipo de desigualdad de manera sencilla contamos con el ingenio suficiente que nos permite evaluar las circunstancias fácticas de la sociedad en cuestión y diseñar la regulación (del impuesto a la herencia de manera) adecuada para encaminarnos a materializar aquello que consideramos justo. Un impuesto a las herencias conforme a los principios de la justicia es, para Rawls, esencial a fin de consolidar la justicia social. Así, según Rawls, la rama

\footnotetext{
${ }^{23}$ Ibíd., 260.

24 Ibíd., 259.

${ }^{25}$ Ibíd., 260.
} 
de distribución en su aspecto correctivo de la distribución de riqueza - que busca evitar amenazas al primer principio de justicia— requiere de un diseño institucional que incluye impuestos a la "donación y sucesión y [que establezca] restricciones a los derechos de herencia"26. De esta forma, estos impuestos no tienen por función recaudar ingresos fiscales sino que, en la teoría de Rawls, desempeñan una función de 'corrección'.

Aquí es interesante notar que la regulación de los derechos de herencia como limitaciones a la propiedad del causante en defensa de la igualdad fue la base que sirvió inicialmente para modificar la regulación del derecho sucesorio dentro del derecho civil ${ }^{27}$. En este sentido, desde que entendemos que la propiedad privada responde a las decisiones políticas de una comunidad o que incluso en aquellos casos en que se ha intentado justificar un derecho de propiedad privada como derecho natural es necesario cumplir con ciertas condiciones para ser titular de ese derecho ${ }^{28}$, se hace más evidente que la propiedad de los herederos es una cuestión que necesita justificación. Más adelante volveré sobre este punto.

Cohen no se refiere de manera directa al impuesto a las herencias como uno de los instrumentos de lo que él llama esquemas de justicia. Pero no es difícil aventurar que un esquema de justicia que refleje de manera adecuada los principios fundamentales de justicia debería contener un impuesto a las herencias. Tal como supone la distinción metodológica establecida en el apartado anterior, la regulación particular de este esquema es una cuestión que dependerá de la forma en que distintos ideales de justicia o virtudes fundamentales de una sociedad se conjugan con las posibilidades que distintos principios de justicia sensibles a las circunstancias fácticas hacen posible. Lo que sí es central es la preponderancia de la justicia distributiva como virtud y la forma en que las desigualdades sociales, que son producto del ejercicio de ciertas libertades, deben ajustarse al criterio de igualdad que las hace aceptables. Cohen no ofrece, a diferencia de Rawls, un estándar para medir

${ }^{26}$ Ibíd., 259.

${ }^{27}$ El análisis de esta evolución en Alemania, Estados Unidos y Francia y las razones políticas que sirvieron de justificación para esta regulación está ampliamente desarrollado en Beckert, Inherited Wealth, 2008.

28 Véase la interpretación de la teoría de la propiedad de Locke en Waldron, The Right to Private Property, 1988, capítulo 6. 
la desigualdad sino que basado en la idea de que la igualdad es una demanda de justicia, supone que existe una demanda ética de comportarse de manera igualitaria. El ethos igualitario de Cohen asume que no sólo se requiere de instituciones (reglas de regulación, en su lenguaje) sino que también es necesario que las decisiones libres de cada uno de los individuos dentro del ámbito regulado por las instituciones respete las demandas de igualdad. Así, por ejemplo, siempre que un grupo de individuos se encuentre en condiciones iniciales de igualdad las diferencias en la distribución de ingresos después de un período o en los distintos momentos en que esta sea una cuestión analizada, deberá responder a elecciones individuales entre ingresos y ocio y no a diferencias en habilidades ${ }^{29}$ o un conjunto de hechos que representen situaciones de mejor o peor suerte (como es ser hijo de quien se es) ${ }^{30}$.

Cuando entendemos que el ideal de igualdad responde a una demanda de justicia y que, por tanto, las desigualdades sociales deben ajustarse a estas demandas de justicia, se hace cada vez más difícil justificar (el derecho a) la herencia. Nótese que bajo este argumento no es siquiera una cuestión relevante la determinación específica de qué entendemos por igualdad o cuáles son las medidas que podrían asegurar cierta igualdad en los intercambios sociales, ya sea de inicio o de resultado $^{31}$, bajo un esquema económico determinado, sino que se trata de una demanda más estricta. En este sentido aquí podemos abandonar a Rawls y el principio de la diferencia y a Cohen y el igualitarismo de suerte, porque basados en sus análisis sobre las desigualdades económicas hemos llegado a mostrar cómo estas dan cuenta de injusticias inaceptables. De esta forma, llevando los argumentos de Rawls y Cohen un paso más adelante, podemos sostener que el igual reconocimiento de cada persona supone que ciertas desigualdades deben eliminarse, puesto que este es el primer paso para determinar qué o cómo materializar, tomando en cuenta las circunstancias de la justicia, ese igual reconocimiento. Nótese además que esto acarrea otra importante consecuencia. Aunque hemos encontrado una justificación al nivel de los principios

${ }^{29}$ Cohen, Rescuing Justice \& Equality, 2008, 110.

${ }^{30}$ Ibíd., 126.

${ }^{31}$ Las discusiones sobre qué tipo de igualdad se busca (ex-post o ex-ante) depende de qué desigualdades se justifican. En este sentido, véase la defensa de la igualdad ex-ante (igualdad de recursos) defendida en Dworkin, Sovereign Virtue, capítulo 2. 
de justicia para corregir una desigualdad social injustificada, nada dice esto respecto de la regulación institucional particular o los efectos que ese diseño podría tener para asegurar el reconocimiento buscado. En otras palabras, hasta aquí nada hemos dicho acerca de las reglas que posibilitarían la eliminación de esta desigualdad de origen. Lo que sí hemos visto hasta aquí es que el impuesto a las herencias no se justifica por razones de recaudación fiscal sino que está directamente conectado con concepciones de justicia política o moral y lo que ellas exigen.

No creo necesario resaltar la injusticia que representa en los términos analizados el hecho de que mis condiciones materiales (sin contar aquí con la herencia cultural) sean una cuestión que sólo se explica por el hecho de ser hijo (o en términos amplios, heredero) de quien soy hijo (o heredero). Aquí se hace evidente que la idea de aplicar un impuesto a la herencia está estrechamente vinculada con la justificación de la propiedad privada y que, por tanto, la regulación de la herencia es una parte de la regulación de la propiedad privada. De esta forma, la herencia no sólo está vinculada con la justificación de la propiedad de los herederos sino también de la posibilidad de determinar la extensión de las potestades que incluye la propiedad del causante. Esto será analizado con algo más de detalle en la sección que sigue. Sólo adelantaré que reconocer un derecho a la herencia implica necesariamente una limitación a la propiedad privada. En consecuencia, adelantando parte del argumento, lo que requiere justificación es la propiedad de los herederos. Para ponerlo en otros términos, el impuesto a las herencias se vuelve relevante cuando entendemos que en términos de justicia no hay buenas razones para justificar la propiedad privada de los herederos en los bienes sobre los que se reconocía un derecho de propiedad al, ahora, causante.

\section{Propiedad privada, potestad de asignar y derecho a la herencia}

Hasta aquí las razones dadas para justificar el impuesto a las herencias suponen o dan por sentado uno de los presupuestos de la discusión, i.e. la existencia de la herencia (y de la potestad del propietario de transferir sin límites a título gratuito). De esta forma, la pregunta por la justificación del impuesto a las herencias sólo parece tener sentido si la herencia está justificada. Sin embargo, al buscar una respuesta para justificar el impuesto a la herencia, hemos visto que los ideales de justicia que sirven de fundamento al impuesto son de tal fuerza que nos llevan 
a cuestionar la herencia. ¿Existen razones para justificar una institución como la herencia? Esta es una pregunta compleja que no espero resolver en este artículo. En términos más generales, esta pregunta es una manifestación de la (ahora, espero, evidente) conexión entre impuestos e instituciones políticas y morales ${ }^{32}$. A pesar de que no podré aquí ofrecer una respuesta completa y detallada a esta pregunta, en lo que sigue exploraré dos posibles respuestas. La primera, asume que la herencia se justifica como una de las potestades que forman parte del derecho de propiedad privada de quien fallece. Llamaré a esta potestad la 'potestad de asignar'. La segunda respuesta supone que se trata de un derecho de los herederos a participar en la propiedad de quien fallece. Llamaré a este derecho el 'derecho a la herencia'33. Veremos que, cualquiera sea el contenido de estas respuestas y a pesar de que el argumento que desarrollo es tentativo, no tenemos buenas razones para justificar la herencia. De esta forma, el impuesto a las herencias aparece como una solución provisoria — un second best ${ }^{34}$ —, esperando por la eliminación de la potestad de asignar y del derecho a la herencia en una sociedad justa.

\section{La potestad de asignar}

La potestad de asignar es una de las potestades que tradicionalmente se entienden incluidas en el derecho de propiedad privada ${ }^{35}$. En particular, esta potestad permite al titular del derecho de propiedad privada determinar la forma en que se distribuye ese derecho. Así, preguntarse por la potestad de asignar sólo tiene sentido dentro de un régimen

32 Véase en este mismo sentido Waldron, "Supply without Burthen Revisited", 1996.

33 Sobre la distinción entre potestades y derechos véase Hohfeld, Conceptos Jurídicos Fundamentales, 1991, 45 y ss.

${ }^{34}$ De acuerdo al teorema del second best "la estrategia para lograr una determinada meta puede asemejarse menos a la primera política (first-policy) que lo que haría una tercera política (third-best policy)", Räikkä, "The Problem of the Second Best: Conceptual Issues”, 2001, 212 (traducción personal). Una conclusión importante del trabajo de Räikkä es que las teorías ideales siguen siendo esenciales para poder evaluar las segundas o terceras alternativas. Vale decir, sólo podemos tener un second best cuando tenemos claridad respecto del ideal.

35 Véase Honoré, Making Law Bind: Essays Legal and Philosophical, 1987, capítulo 8 “Ownership”, en especial 171-173. Honoré llama a esta potestad, utilizando términos técnico-jurídicos, "el incidente de la transmisibilidad". 
de propiedad que reconoce la propiedad privada. En una comunidad política en que se ha adoptado un régimen comunal o socialista de propiedad este problema no se presenta porque no se reconoce la potestad de asignar dentro del derecho de propiedad. Lo que interesa para efectos de este artículo es determinar si está justificado un caso específico de la potestad de asignar: aquel en que el titular del derecho de propiedad puede determinar la distribución del mismo con efectos póstumos (y aquellos casos en que la asignación antes de la muerte está motivada por razones de mera gratuidad entre parientes).

Según Jeremy Waldron el concepto de propiedad, del que existen diversas concepciones, está formado por un "sistema de reglas que determinan el acceso y el control [sobre distintos] recursos materiales" ${ }^{\text {"3 }}$. En toda sociedad en que los recursos materiales son escasos y se busca vivir en paz, el principal problema que los sistemas de propiedad buscan resolver, sostiene Waldron, es el de la asignación de estos bienes. A su juicio, los sistemas de propiedad no incluyen todas las reglas referentes al uso de estos recursos, pero sí aquellas que se refieren a la asignación de los mismos ${ }^{37}$. Un sistema de propiedad privada, entonces, está compuesto por reglas que determinan que existe un vínculo de pertenencia entre un bien y un individuo determinado. De esta forma, en este tipo de sistemas, el problema de la asignación de bienes se resuelve estableciendo "una regla conforme a la cual, respecto de cada objeto, la persona cuyo nombre está unida a ese objeto determina cómo y por quién ha de usarse el objeto" 38 .

La cuestión que interesa acá determinar es si la potestad de asignar con efectos póstumos debe entenderse incluida en el derecho de propiedad privada (o si la asignación gratuita en vida entre parientes debería tener restricciones). Este es un problema que no podré resolver aquí. Sin embargo, me interesa hacer una aclaración y esbozar una respuesta. Primero la aclaración. Es importante no confundir la cuestión que aquí discuto con otra que se refiere a los posibles derechos que se reconocen a quien muere ${ }^{39}$. Este último es un problema que se ha planteado en discusiones acerca de la protección que merece el cuerpo después de la muerte o sobre la protección de la honra de quien muere. Pero, ¿por

\footnotetext{
${ }^{36}$ Waldron, The Right to Private Property, 1988, 31 (traducción personal).

37 Ibíd., 32.

${ }^{38}$ Ibíd., 39 (traducción personal).

${ }^{39}$ Véase Sperling, Posthumous Interests: Legal and Ethical Perspectives,
} 2008,55 y ss. 
qué no incluir el problema que nos interesa resolver entre este tipo de cuestiones? La respuesta es clara; porque no se trata del mismo tipo de problema. La confusión se produce entre aquellos que entienden que estos casos son equiparables porque pueden resolverse atendiendo exclusivamente a la noción de derechos subjetivos ${ }^{40}$. Así, la discusión se concentra en determinar qué teoría de los derechos subjetivos mejor cubre estos casos o si es necesario crear nuevas categorías de derechos subjetivos para incluir los "intereses póstumos" de "sujetos humanos"41. En otras palabras, se trata de problemas distintos porque, en lo que aquí interesa, estamos tratando de determinar aquello que debería incluir el concepto de (derecho de) propiedad privada. En términos más precisos, la cuestión en disputa es si el derecho de propiedad privada debería incluir la potestad de asignar con efectos póstumos. De esta forma, tenemos que distinguir entre aquello que consideramos importante cuando se trata de determinar el estatus de quienes han fallecido y aquello que dice relación con la determinación de la extensión del derecho de propiedad privada. No se trata, entonces, de si debemos reconocer o no la voluntad del causante sino de determinar una cuestión previa, i.e. si es razonable entender que debemos reconocer la potestad de asignar con efectos póstumos como una de las potestades que justifican la propiedad privada que reconocemos a una persona ${ }^{42}$.

Hecha la aclaración ahora puedo esbozar una respuesta a la pregunta sobre los efectos póstumos de la potestad de asignar. Como es sabido, existen muchas teorías que buscan justificar la propiedad privada. Por razones de espacio no puedo aquí desarrollar en detalle estas alternativas, optar por una de ellas, u ofrecer una nueva justificación. Sin embargo, me parece que cualquiera sea la justificación de la propiedad privada que se adopte, si se ha de tener en consideración la función

40 Así lo hace Steiner, An Essay on Rights, 1994, 249-261. Como el mismo Steiner sostiene, esta es una cuestión secundaria puesto que podríamos utilizar una "ficción jurídica" para resolver el problema (y evitar que los bienes se consideren res nullius). Esta solución, sin embargo, no resuelve el problema que aquí nos preocupa.

${ }^{41}$ Sperling, Posthumous Interests: Legal and Ethical Perspectives, capítulos 1 y 2 .

${ }^{42}$ Cécile Fabre entiende que este es un tipo de problema que puede resolverse exclusivamente en atención al concepto de derechos, reconociéndolos como derechos sujetos a condición. Así, comete el mismo error que Steiner, An Essay on Rights, 1994, 249-261. Véase Fabre, "The Choice-Based Right to Bequeath", 2001, y de la misma, "Posthumous Rights", 2008. 
de la propiedad privada, ya sea como condición para el funcionamiento de una economía de mercado o reconociéndole una vinculación con el desarrollo ético de los individuos, la potestad de determinar de forma póstuma cómo han de ser esos bienes distribuidos no es necesaria para esos efectos. Esto es así porque podemos encontrar algún arreglo institucional distinto del que supone reconocer lo que aquí he llamado la potestad de asignar en el derecho de propiedad privada. Quienes defienden que esta potestad debe ser parte del derecho de propiedad privada necesitan justificar que el mejor arreglo institucional para resolver el problema que la muerte implica, i.e. la separación del titular del derecho y el objeto sobre el que recae la propiedad, es que ciertas personas puedan determinar con efectos póstumos quiénes han de ser titulares de ese derecho. En otros términos, quienes defienden la potestad de asignar, necesitan justificar por qué resuelven este problema mediante la conservación de una posición de privilegio, i.e., la posibilidad de determinar, con independencia de los arreglos políticos de una comunidad política, la distribución de ciertos bienes en beneficio de alguna(s) persona(s).

\section{El derecho a la herencia}

El derecho a la herencia puede ser entendido como el derecho que los herederos tienen en la propiedad del causante. Reconocer este derecho implicaría establecer inmediatamente un límite a las potestades del propietario en un régimen de propiedad privada; en particular, se trataría de una limitación a la potestad de asignar. Si los herederos tienen un derecho en la propiedad del causante, éste no puede disponer de sus bienes con efecto póstumo como le plazca sino que debe respetar el derecho de los herederos.

Aquí puede ser útil revisar la distinción que desarrolla Waldron, en The Right to Private Property, entre teorías que justifican el derecho de propiedad como un derecho especial y aquellas que lo justifican como un derecho general ${ }^{43}$. En el primer caso, el derecho de propiedad se reconoce sólo cuando existe un hecho positivo que vincule a una persona con una cosa sobre la que recae el derecho. En el segundo, el derecho de propiedad es un derecho general puesto que se reconoce por la importancia que en sí mismo tiene el derecho para las personas,

${ }^{43}$ Waldron, The Right to Private Property, 1988, capítulo 4. 
con independencia de lo que éstas hagan ${ }^{44}$. Según Waldron, una de las teorías en que el derecho de propiedad es un derecho especial es la de Locke, mientras que una en que el derecho de propiedad es un derecho general es la de Hegel.

En este esquema el derecho a la herencia parece no tener justificación. Para ser un derecho especial la acción imputable a los herederos tendría que ser distinta de aquella que funda las relaciones que dan lugar a la herencia porque éstas son completamente independientes de su acción, i.e. ser hijos o parientes de quienes son. Por otra parte, si el derecho a la herencia se considera como un derecho general, no existe razón para discriminar entre quienes pueden ocupar la posición de heredero y quienes no, i.e. todos seríamos potenciales herederos de todos. En consecuencia, pareciera que no hay respaldo para justificar el derecho a la herencia siguiendo las teorías de la propiedad privada como derecho.

A pesar de lo anterior, todavía podría haber espacio para una justificación del derecho a la herencia. Para ello el derecho a la herencia tendría que justificarse como un derecho especial que deriva de las relaciones filiales. En este sentido, se trataría de un derecho que tendría como correlativo el deber de los padres de proveer condiciones materiales suficientes para el desarrollo y sustento de los hijos. Así, por ejemplo en Locke, este deber es correlativo del derecho de preservación que corresponde a los hijos ${ }^{45}$. Este derecho es uno de los derechos naturales que se impone sobre el derecho de propiedad. Buscando interpretar la coexistencia de estos derechos en la teoría de Locke, Jeremy Waldron sostiene que se trata de un argumento desarrollado por Locke contra la doctrina de la primogenitura defendida por Sir Robert Filmer. Con el fundamento lockeano del derecho a la herencia no hay espacio para distinguir entre hijos con mejor y peor derecho. Es en este sentido igualitario que para Locke la familia constituye la unidad económica relevante ${ }^{46}$. En los términos de Locke el derecho de los hijos a ser mantenidos por sus padres limita incluso la posibilidad de que éstos enajenen libremente su propiedad ${ }^{47}$. En conclusión, en la

44 Ibíd., 115-116.

45 Véase $\S 88$ del First Treatise of Government. La versión que revisé está en Locke y Shapiro, Two Treatises of Government; and a Letter Concerning Toleration, 57.

46 Waldron, The Right to Private Property, 1988, 241-251; y del mismo, "Locke's Account of Inheritance and Bequest", 43.

47 Ibíd., 44. 
teoría de Locke, el derecho a la herencia busca que los hijos tengan las condiciones materiales necesarias para su desarrollo y que por estas razones todos sean tratados (entre ellos) como iguales en su necesidad. Si esto es así, el derecho a la herencia deja de tener sentido una vez que los hijos están en condiciones de satisfacer sus necesidades por sí mismos. Pero podemos incluso ir más allá y sostener que en caso que existan, como ocurre en la legislación vigente en Chile, arreglos institucionales que satisfagan este derecho de los hijos en términos equivalentes, v.gr. derecho de alimentos, el derecho a la herencia pierde su importancia.

De lo hasta aquí señalado, me parece que el impuesto a las herencias es necesario mientras sigamos reconociendo la potestad de asignar o el derecho a la herencia. En este sentido, este impuesto muestra que la potestad de asignar con efectos póstumos es injustificada y que toleramos la propiedad de los herederos en los bienes del causante a pesar de adolecer de justificación. Este impuesto es una manifestación adecuada, aunque insuficiente, del igual reconocimiento que se deben los miembros de una comunidad política. Que yo sea quien soy, como premisa sobre la cual justificar mi propiedad, sólo es relevante una vez que asumimos que ciertas condiciones que nos ponen en circunstancias de igualdad hacen posible esa afirmación. Que tenga lo que tengo, en comparación a otros, sólo puede estar justificado — si puede justificarse - una vez que mi historia familiar es irrelevante para ser quien soy en términos patrimoniales.

\section{Críticas estériles e injustificadas}

Veamos ahora cómo responder a las críticas formuladas contra el impuesto a las herencias en Chile. Para ello intentaré aplicar la distinción entre los niveles de justificación que hemos analizado hasta aquí, i.e. de primeros principios o ideales de justicia, y el nivel de regulación institucional. Si bien en principio pareciera que el tipo de críticas formuladas está dirigido exclusivamente a la regulación positiva del impuesto a las herencias en Chile, las consecuencias que se esgrimen como elementos relevantes para sostener estas críticas permiten interpretar que, en su mejor versión, reconocen los dos niveles de justificación. Para ponerlo en otros términos, al no contar con una formulación adecuada de las críticas que reconozca los niveles de análisis aquí desarrollados, no es posible discutir en detalle los argumentos que podrían 
desarrollarse en el nivel de los ideales de justicia. A pesar de ello, veremos que tras las críticas es posible interpretar que los argumentos provienen de cierta concepción de la justicia y que para poder tener algún peso argumentativo requieren de mayor justificación ${ }^{48}$.

Uno de los argumentos que genera mayor apoyo por parte de los críticos del impuesto a las herencias es que se trata de un impuesto patrimonial y que implica una doble tributación, según lo descrito antes en las letras (a) y (b) del apartado I. En (a) la crítica es, como espero demostrar, errada. Respecto de (b) se trata de una mera cuestión de regulación.

\section{(a') La constitución chilena no prohíbe los impuestos al patrimonio}

Quienes defienden el primer argumento sostienen que el artículo $19 \mathrm{~N}^{\circ} 20$ del texto constitucional (DL 3464 de 1980) establecería una limitación a la posibilidad de que el sistema tributario chileno incluyera impuestos al patrimonio. Ésta es la premisa mayor de un argumento que luego tiene como premisa intermedia una clasificación de los tributos - entre las muchas posibles - para sostener que el impuesto a las herencias en Chile, con independencia de su regulación particular, es un impuesto al patrimonio y, por tanto, sigue la conclusión, el impuesto a las herencias sería un impuesto al patrimonio que va en contra de la regulación constitucional. En lo que sigue, parto por demostrar que las premisas de este argumento son falsas.

En primer lugar, la regulación constitucional-tributaria no prohíbe ni establece una limitación que afecte el establecimiento de impuestos al patrimonio. Por el contrario, la constitución confiere al Presidente la República la iniciativa exclusiva para, mediante ley, "[i]mponer, suprimir, reducir o condonar tributos de cualquier clase o naturaleza, establecer exenciones o modificar las existentes, y determinar su forma, proporcionalidad o progresión”49. Así, la constitución confiere al Presi-

48 Además de ser una defensa de la justicia de un impuesto a las herencias en términos de principios y de la regulación vigente del impuesto a las herencias en Chile, este artículo puede interpretarse como una invitación para que los críticos de esta institución desarrollen los principios de justicia y los argumentos al nivel de la regulación que sostienen su posición.

${ }^{49}$ Art. 65 inc. 4, No 1, DL 100 publicado en el Diario Oficial el 22/09/05 (destacado agregado). 
dente de la República la potestad para establecer, mediante una ley de su iniciativa exclusiva, tributos de cualquier clase o naturaleza. Esta es una cuestión importante de aclarar y de compatibilizar con lo establecido en el artículo $19 \mathrm{~N}^{\mathrm{o}} 20$ del texto constitucional que contiene algunos de los principios constitucionales en materia tributaria ${ }^{50}$. En particular, en esta norma se contienen los siguientes principios constitucionales: (i) la igual repartición de los tributos y las cargas públicas (inc. $1^{\circ}$ ); (ii) el principio de legalidad en materia tributaria (inc. $\left.1^{o}\right)^{51}$; (iii) el principio de proporcionalidad en materia tributaria (inc. $\left.2^{\circ}\right)^{52}$; (iv) el principio de no afectación de los tributos (inc. $\left.3^{\circ}\right)^{53}$; y, finalmente, el inciso cuarto establece una excepción al principio de la no afectación ${ }^{54}$.

El problema radicaría, según la interpretación que aquí se critica, en que el artículo $19 \mathrm{~N}^{\circ} 20$ se refiere a "la igual repartición de los tributos en proporción a las rentas [...]". Esto implicaría que la constitución prohibiría establecer tributos de otra clase o naturaleza, v.gr. los impuestos al patrimonio y entre éstos un impuesto a la herencia. ¿Es esta la mejor interpretación de las normas constitucionales vigentes? Mi impresión es que no. Al revisar las normas vigentes (y sus antecedentes desde el DL 3464 de 1980 en adelante, que no han sido modificadas) y la discusión que precedió a la dictación de las normas del DL 3464 de 1980 en la Comisión de Estudios de la Nueva Constitución (CENC) se observa que nunca se pretendió prohibir los impuestos al patrimonio, sino que por el contrario siempre se pensó en aclarar que este tipo de impuestos no contravenía las disposiciones constitucionales. Así, en la

50 Sobre esta materia, véase, en general, Evans y Evans, Los Tributos ante la Constitución, 1997.

51 "La igual repartición de los tributos en proporción a las rentas o en la progresión o forma que fije la ley, y la igual repartición de las demás cargas públicas".

52 "En ningún caso la ley podrá establecer tributos manifiestamente desproporcionados o injustos".

53 "Los tributos que se recauden, cualquiera que sea su naturaleza, ingresarán al patrimonio de la Nación y no podrán estar afectos a un destino determinado".

54 “Sin embargo, la ley podrá autorizar que determinados tributos puedan estar afectados a fines propios de la defensa nacional. Asimismo, podrá autorizar que los que gravan actividades o bienes que tengan una clara identificación regional o local puedan ser aplicados, dentro de los marcos que la misma ley señale, por las autoridades regionales o comunales para el financiamiento de obras de desarrollo". 
discusión que tuvo lugar en la CENC sólo se mencionan los impuestos al patrimonio cuando se discutió sobre el principio constitucional de proporcionalidad de los tributos. Más aún, todas las referencias a los impuestos al patrimonio se hicieron para mostrar que, en principio, son impuestos que no implican necesariamente un problema de proporcionalidad. Así, en la discusión sobre la norma constitucional que reemplazaría a la del número 1 del artículo 44 de la Constitución de 1925, y en particular al discutir sobre los límites que deberían establecerse para que el ejercicio de la potestad de establecer tributos no afectara al derecho de propiedad en su esencia (como sería consagrado finalmente en el artículo $19 \mathrm{~N}^{\mathrm{0}} 26$ ), el señor Guzmán señaló que no se podía “aprobar el inciso [que más tarde sería el actual inciso segundo] sin dejar constancia de una excepción, en el sentido que se autorizan los impuestos al patrimonio, lo cual constituye, de alguna manera, una confiscación"55. Por ahora podemos dejar en suspenso la afirmación de que los impuestos al patrimonio constituyen "de alguna manera una confiscación", que será analizada más adelante. Lo que me interesa destacar de la afirmación del señor Guzmán es que, en principio, la exigencia de proporcionalidad en los tributos no impide el establecimiento de impuestos al patrimonio. En la misma sesión de la CENC el señor Bertelsen se refirió indirectamente a los impuestos a la herencia al proponer "que la Carta disponga que los impuestos deberán recaer sobre los ingresos", aunque al mismo tiempo "reconoce que existen algunos que gravan el patrimonio, tales como los de herencia y de bienes raíces" ${ }^{56}$. A renglón seguido, la señora Romo sugirió que estos impuestos (a la herencia y el de bienes raíces) quedaran sujetos a la misma limitación (de proporcionalidad) porque "de otro modo podían tener un carácter expropiatorio" 57 . De esta forma vemos que en la CENC nunca se puso en duda la posibilidad de que existieran impuestos al patrimonio. Lo que sí se pretendió es que ningún tributo fuera "manifiestamente desproporcionado o injusto" y esta injusticia o desproporción depende de que el derecho de propiedad no

55 Actas oficiales de la Comisión de Estudio de la Nueva Constitución Política de la República, Sesión 384, celebrada el 14 de Junio de 1978.

56 Ibíd.

57 Ibíd. Evidentemente en este caso no puede haber expropiación en sentido técnico jurídico, porque se requeriría compensación. La señora Romo se refería a lo que en la CENC se discutió como confiscación (afectación de la propiedad en su esencia). 
se afecte en su esencia (y esto, claro está, dependerá de la regulación específica de un determinado tributo).

Entonces, ¿cómo interpretar la referencia a las "rentas" en la primera parte del inciso primero del artículo 19 No 20 de la constitución? De lo antes señalado, todo parece indicar que se trata de un caso de error en la expresión que hace que esta norma sea incoherente dentro del sistema constitucional-tributario. Hay otros casos en el sistema jurídico chileno en que encontramos errores similares. Por ejemplo, el Código Civil muchas veces dice "tradición" cuando quiere decir "entrega"; o en la constitución, cuando dice "promulgado" (en el inciso octavo del artículo $19 \mathrm{~N}^{\circ}$ 3) queriendo decir "entrado en vigencia", en lugar del participio del verbo promulgar en el sentido de la propia constitución ${ }^{58}$. Así, si uno interpreta correctamente la referencia antes citada a las palabras del señor Bertelsen durante la discusión sobre la regulación constitucional-tributaria que tuvo lugar en la CENC, aquellas en que sugería que la constitución dispusiera que los impuestos recayeran sobre los "ingresos", ésta sería una forma, equivocada, de resaltar que los impuestos no debían ser "confiscatorios" (manifiestamente desproporcionados o injustos de forma que pongan en riesgo el derecho de propiedad en su esencia). De esta forma, la solución interpretativa consiste en reemplazar dicha expresión: ahí donde el 19 No 20 del texto constitucional señala "rentas", debería leerse "haberes" tal como lo decía la regulación contenida en la Constitución de 1925. Con esta interpretación no sólo se logra mantener la sistematicidad y coherencia del conjunto de normas constitucionales en materia tributaria (¿de qué otra forma interpretar el contenido de la norma que confiere iniciativa exclusiva de ley al Presidente de la República en esta materia?), sino también del sistema tributario vigente en Chile (¿cómo entender que en Chile existan impuestos al consumo?). Lo contrario supondría que en la constitución está regulada de manera detallada una parte importante de la política económica en materia fiscal del gobierno de turno, en particular, el tipo de impuestos con que puede contar un determinado gobierno para financiar el gasto público. En otras palabras, de no rectificarse la expresión "rentas" en los términos propuestos, en Chile sólo podría haber tributos a la renta. Esta interpretación desconocería que la constitución delega en la ley, de iniciativa exclusiva del Presidente de la República, el establecimiento de la forma en que los ciudadanos han de concurrir en la igual repartición de los tributos. Con esta interpretación,

${ }^{58}$ Agradezco estos ejemplos a Fernando Atria y Antonio Bascuñán. 
además, queda claro que el propósito del artículo $19 \mathrm{~N}^{\circ} 20$ no es especificar qué tipo de tributos pueden ser creados por ley, sino asegurar a cada uno la debida igualdad en su formulación y aplicación.

En definitiva, la constitución confiere al Presidente de la República la potestad de "[i]mponer, suprimir, reducir o condonar tributos de cualquier clase o naturaleza, establecer exenciones o modificar las existentes, y determinar su forma, proporcionalidad o progresión" 59 bajo las condiciones establecidas en el artículo $19 \mathrm{~N}^{\mathrm{o}} 20$, vale decir, el Presidente deberá ejercer esta potestad mediante ley, respecto de la cual tiene iniciativa exclusiva, procurando asegurar la igual repartición de las cargas públicas, sin establecer tributos manifiestamente desproporcionados o injustos (i.e. que no ponga en riesgo el derecho de propiedad en su esencia), y sin afectarlos a un determinado fin (a menos que se trate de una de las excepciones a las que se refiere el mismo artículo). De esta forma queda demostrado que la primera premisa de la crítica (a) no se sostiene. Así, la regulación constitucional-tributaria no prohíbe los impuestos al patrimonio.

Ahora revisemos la premisa intermedia, ¿es el impuesto a la herencia un impuesto al patrimonio? La respuesta es: depende. La respuesta depende de dos factores: (i) la definición de impuestos al patrimonio; y (ii) de la regulación del impuesto en cuestión. Entonces, como se ha venido argumentando en este artículo, que el impuesto a las herencias sea o no un impuesto al patrimonio dependerá de los principios de justicia y de la regulación particular que se adopte. En Chile, como espero demostrar en lo que sigue, el impuesto a las herencias - conforme a la legislación vigente- no es un impuesto al patrimonio.

La doctrina económica más tradicional clasifica los distintos tipos de tributos en aquellos que gravan el consumo, la renta o el patrimonio. Se trata evidentemente de distinciones que surgen a partir del análisis de las distintas posibilidades institucionales que dan lugar a los tributos. Vale decir, no se trata de una descripción de un fenómeno de la naturaleza o de una categoría que sea independiente de las decisiones contingentes respecto de aquello sobre lo cual se exigirá la contribución del ciudadano. Son categorías que pueden surgir del análisis económico de las distintas fuentes de los tributos o de la descripción de los arreglos

${ }^{59}$ Art. 65 inc. 4, № 1, DL 100 publicado en el Diario Oficial el 22/09/05. (Destacado agregado.) 
institucionales vigentes. En el primer caso, se trata de distinciones que permiten más o menos determinar el impacto de un tributo conforme a un orden ideal de los arreglos económicos existentes, lo que dependerá de la teoría de la justicia que se adopte. En el segundo, en cambio, la regulación particular de un tributo que conforme al orden ideal debería corresponder a un tipo de tributo (por ejemplo, al patrimonio) termina mostrando que se trata de uno distinto (por ejemplo, a la renta). En lo que sigue desarrollo estas ideas.

Antes de comenzar el análisis de la categoría ideal de impuestos al patrimonio quiero introducir una aclaración conceptual. La doctrina económica comparada se refiere a este tipo ideal de impuestos según la denominación en inglés wealth taxes. Esta etiqueta me parece más clara para dar cuenta de lo que se intenta categorizar. Por eso en lo que sigue abandonaré la mención a los impuestos al patrimonio y la reemplazaré por "impuestos a la riqueza". Esta aclaración muestra de inmediato que no existe, como se tiende a creer en nuestro país, una equivalencia entre impuestos a la riqueza y tributos "confiscatorios". De esta forma respondemos al problema del señor Guzmán que consta en las actas de la CENC antes mencionado, i.e. que los impuestos al patrimonio son “de alguna manera una confiscación”. En este sentido, puede haber dos interpretaciones: los impuestos a la riqueza serían una especie de "confiscación" (como son todos los tributos para algunas teorías de la justicia), pero como hemos visto antes esto no es problema; sin importar la teoría de la propiedad privada que se defienda, lo que la constitución busca es evitar que la obligación de contribuir a las cargas públicas afecte a este derecho en su esencia. La segunda, es que se trate de una especie de "confiscación" porque se aplican sobre el patrimonio en sentido jurídico; sin embargo, como vemos, se trata de una categoría económica que busca gravar la riqueza. Así, un impuesto a la riqueza (o cualquier otro tributo), como creo es evidente, no pone necesariamente en riesgo la propiedad privada ni es "confiscatorio" en una interpretación jurídica.

En su definición más amplia, los impuestos a la riqueza son aquellos que se aplican sobre la riqueza inmovilizada (el stock) y no sobre los flujos de ingreso o consumo ${ }^{60}$. Así, por ejemplo, “[e]ste tipo

${ }^{60}$ Mintz, "The Role of Wealth Taxation in the Overall Tax System", $1991,259$. 
de impuestos puede imponerse sobre porciones de propiedad inmueble (que deben ser pagados por el propietario) y en consecuencia ser impersonales, de tipo in rem; o puede imponerse sobre la combinación total de la propiedad que una persona posea, o sobre su riqueza neta, siendo entonces de aquellos que tienen naturaleza personal" ${ }^{\prime 2}$. De esta forma, dependiendo de los arreglos institucionales — de la regulación — puede haber muchos tipos de impuestos a la riqueza. Así por ejemplo, en la sistematización desarrollada por Mintz se encuentran tres categorías con distintos tipos de tributos. La primera está compuesta por aquellos que se aplican sobre la propiedad de activos. Entre estos se incluyen: los impuestos a la propiedad de activos, un impuesto al capital sobre los activos, una tasa sobre el capital y los impuestos a la propiedad inmueble. La segunda categoría está compuesta por aquellos tributos que se aplican a las transferencias de riqueza. Esta categoría comprende impuestos tales como: los impuestos a la herencia (en sus diversas posibles configuraciones institucionales) y a las donaciones, y los impuestos a las transferencias. La tercera categoría es la de los tributos sobre las adquisiciones. Aquí Mintz incluye un impuesto especial sobre los bienes de capital y un impuesto sobre los gastos capitalizados (gastos en los que se incurriría equivalentes al goce del activo $)^{62}$. Esta clasificación económica es independiente de la regulación específica que existe en una determinada comunidad política. Así, la distinción entre tributos al consumo, al ingreso o a la riqueza atiende a las fuentes económicas vistas en un sentido dinámico, i.e. depende de si se trata de flujos o un stock económico. Ahora bien, si lo que se busca es describir los tributos que existen en un determinado momento en una determinada comunidad política, los criterios de justicia que subyacen a la regulación y la regulación de los tributos en sí mismos, hacen más confusa la nitidez de estas categorías. Así, existen tributos a la riqueza que son compatibles y se acercan más a los impuestos al consumo o a la renta una vez que atendemos a los criterios de justicia y a su regulación. De esta forma,

${ }^{61}$ Musgrave, Musgrave y Bird, Public Finance in Theory and Practice, 1987, 429 (traducción personal). Una definición alternativa citada por Mintz en "The Role of Wealth Taxation in the Overall Tax System", 1991, es la de Boadway y Wildasin: para ellos la riqueza es "el stock de poder adquisitivo que un individuo ha acumulado. En principio, la riqueza de un individuo es el valor presente de su flujo de ingreso futuro" (Public Sector Economics, 1984, 269).

${ }^{6}$ Mintz, "The Role of Wealth Taxation in the Overall Tax System", 1991, 250-1. 
según Mintz, "[s]i el objetivo final del gobierno es que los individuos contribuyan según su capacidad contributiva, se ha argumentado que la mejor medida del bienestar de un individuo es la base imponible sobre el ingreso comprehensivo. El ingreso comprehensivo puede definirse como el ingreso del trabajo (remuneración, salarios y otros beneficios) y los cambios en la riqueza neta de la unidad familiar. El último puede ser medido como ingresos del capital (dividendos, intereses y ganancias de capital acumuladas) y [...] las donaciones y las herencias recibidas" ${ }^{\prime 3}$. Luego de analizar algunos argumentos de justicia y económicos, Mintz concluye que las "herencias deberían ser gravadas como ingresos" $" 64$. Al mismo resultado, esta vez desde una perspectiva de welfare economics, llega Kaplow ${ }^{65}$ cuando sostiene "aun cuando en ocasiones son vistos como una forma distinta de tributación, los impuestos a la riqueza son simplemente, una vez examinados, una forma de imposición a los ingresos del capital"66. Así, por ejemplo, para los defensores del welfare economics aplicado a la política tributaria poco importa la fuente a la que se aplica el tributo, lo que es relevante es determinar si la política tributaria cumple con los requerimientos de la "imposición (o tributación) óptima" en atención a la "función social de bienestar" "67.

En otras palabras, las clasificaciones de las distintas formas que puede adoptar un tributo, esto es, la clasificación de las distintas decisiones de política tributaria, dependen del marco bajo el cual se evalúa dicha política. En consecuencia, la clasificación de un tributo en aquellos que gravan los ingresos, el consumo o la riqueza puede o no ser clarificadora dependiendo de la perspectiva adoptada. Así, la clasificación será o no útil dependiendo de su capacidad para explicar aquello que se quiere justificar o describir y no al contrario, i.e. la categoría no define la forma que adopta la política tributaria, sino que la política tributaria define cuán perspicua es una categoría que pretende explicarla. removidas).

${ }^{63}$ Ibíd., 253 (traducción personal; las referencias del original fueron ${ }^{64}$ Ibíd., 257.

${ }^{65}$ Véase Kaplow, The Theory of Taxation and Public Economics, 2008, capítulo 9; en especial, 235 y ss.

66 Ibíd., 235. En el mismo sentido Kaplow cita a Atkinson y Stiglitz, Lectures on Public Economics, 1980.

${ }^{67}$ Kaplow, The Theory of Taxation and Public Economics, 2008, capítulos 2 y 3 . 
Esto permite mostrar con más claridad la discusión que se ha dado sobre los impuestos a la riqueza, por ejemplo, en Estados Unidos. La discusión en ese país consiste en encontrar una justificación para los impuestos a la riqueza, en sí mismos o en combinación con impuestos a la renta y los impuestos al consumo. Así, la principal discusión se da respecto de la justificación (en términos de teorías de la justicia y los argumentos económicos que de ellas se derivan) de los impuestos a la riqueza que gravan los ahorros de una persona ${ }^{68}$. Pero no respecto de la justificación de aquellos impuestos a la riqueza que se aplican sobre la transferencia gratuita, en especial respecto de aquellos que se aplican sobre las asignaciones hereditarias y respecto de los que el deudor tributario es el asignatario. Se trataría en estos casos de impuestos que gravan el flujo recibido (la fuente de este flujo es una riqueza, pero esto difícilmente permite calificar el impuesto como uno al "patrimonio") que se asemeja más a un impuesto a la renta en sentido amplio ${ }^{69}$.

En definitiva, para sostener que un tributo es un impuesto al patrimonio es necesario justificar esa afirmación en: (i) una determinada teoría de la justicia, que supone una determinada concepción de la propiedad privada; (ii) una teoría económica que asuma ciertas definiciones derivadas de lo anterior; y, (iii) una determinada regulación. Como muestro más adelante, el impuesto a las herencias vigente en Chile no es un impuesto al "patrimonio" sino que un impuesto que se aplica al flujo de riqueza que recibe un asignatario.

\section{(b') El impuesto a las herencias vigente en Chile no grava dos veces el mismo patrimonio}

Para contestar la crítica (b) - aquella según la cual el impuesto a las herencias vigente en Chile grava dos veces el mismo patrimoniodebemos, en primer lugar, determinar si el impuesto a las herencias es

${ }^{68}$ En Europa, en cambio, este tipo de impuestos a la riqueza no genera los mismos problemas de justificación. Así, por ejemplo, la evolución de la regulación del impuesto al patrimonio en Francia muestra su dependencia de las decisiones políticas: el impuesto fue introducido por primera vez por un gobierno socialista, derogado por un gobierno de derecha, y vuelto a establecer por un gobierno socialista. Véase, Lehner, "The European Experience with a Wealth Tax: A Comparative Discussion”, 1999-2000.

${ }^{69}$ Véase en este sentido Rakowski, "Can Wealth Taxes be Justified?", 1999-2000. 
un impuesto a la riqueza; para luego determinar si el impuesto a las herencias grava dos veces la misma riqueza produciendo una doble tributación. Como hemos visto más arriba, la primera cuestión dependerá de la regulación particular de que se trate. Si asumimos, como parece razonable, que esta crítica se aplica al impuesto a las herencias vigente en Chile, la respuesta es: no. El impuesto a las herencias en Chile no es un impuesto a la riqueza sino que se asemeja más a un impuesto al ingreso de los herederos.

En general, el diseño institucional de los impuestos a la herencia es una cuestión, tal como ha sido señalado más arriba ${ }^{70}$, que puede variar dependiendo de ciertas restricciones fácticas y la concurrencia de distintos ideales políticos ${ }^{71}$. Para dejar atrás la crítica (b) es suficiente notar que en Chile la regulación del impuesto a la herencia recoge y se explica mejor conforme a los principios de justicia desarrollados en este artículo y, en consecuencia, está lejos de ser entendida como una que se aplica sobre la riqueza ("el patrimonio") del causante. Recordemos que por las razones de justicia expuestas en este trabajo, ha quedado demostrado que el impuesto a las herencias se vuelve necesario mientras en una comunidad política exista algún tipo de derecho a la herencia o alguna potestad de asignar como parte del derecho de propiedad privada. Lo que estos argumentos muestran es que el hecho que se busca gravar con el impuesto en cuestión no es la detentación de una determinada riqueza en el tiempo (un stock), sino el hecho que haya habido una transferencia que desde el punto de vista de la justicia no debió haber, i.e. aquella que se produce entre causante y heredero. Así, conforme a la legislación vigente en Chile, el impuesto se aplica sobre el valor líquido de cada asignación y el obligado al pago es el asignatario (art. 2 y 50 bis, Ley 16271) ${ }^{72}$. Se trata de un impuesto que no grava la riqueza del causante (ni tampoco la riqueza previa del heredero) sino que el aumento patrimonial que representa el valor líquido de la asignación para el heredero, vale decir, el flujo (y no el stock) que supone la transferencia

${ }^{70}$ Véase supra nota 8.

71 Sobre las diferentes formas que puede adoptar un impuesto a las herencias, véase Rudnik y Gordon, “Taxation of Wealth”, 2000.

72 En el derecho comparado se ha entendido que incluso en aquellos casos en que el impuesto se aplica a la totalidad del patrimonio del causante, no se trataría de un impuesto al patrimonio (incluso en términos morales) porque los obligados al pago son necesariamente los herederos, así White, "What (If Anything) Is Wrong with Inheritance Tax?”, 2008, 163-164. 
de la herencia ${ }^{73}$. Por la misma razón, para no aplicar impuestos dos veces sobre el mismo hecho, según lo establecido en el artículo 17 № 9 de la Ley de la Renta (contenida en el artículo $1^{\circ}$, DL 824), no constituye renta la adquisición de bienes por sucesión por causa de muerte ${ }^{74}$.

Lo anterior implica descartar de inmediato (b). El impuesto a las herencias no grava dos veces la misa riqueza (o el mismo "patrimonio"). Sin embargo, esto parece no dejar satisfechos a algunos. Quienes insisten en que se trataría de un caso de doble tributación sobre una riqueza que ya ha pagado impuestos, parecen defender un argumento de justicia al señalar que la familia ha ayudado históricamente en la creación de esa riqueza y por tanto no se debería aplicar el impuesto. Este argumento es absurdo. En primer lugar, suponer que no deberían aplicarse impuestos sobre una riqueza que ya ha pagado impuestos supondría que todos los impuestos que se aplican en un momento (T2), una vez que la riqueza que se ha producido inicialmente en el mercado (T1) es imposible de identificar, serían injustos. Parece difícil entender que alguien defienda esta idea como una de justicia. Esto es equivalente a sostener, por ejemplo, que si al comprar un bien estamos obligados a pagar el impuesto a las ventas y servicios (el IVA) en T2, habiendo ya pagado el impuesto global complementario en T1, el IVA sería en ese caso un impuesto al "patrimonio" (y lo gravaría dos veces); o que, dejando de lado las particularidades del impuesto a la renta en la determinación de la renta líquida imponible, cada vez que un socio de una sociedad de personas que recibe un sueldo como empleado de su propia sociedad debe pagar el impuesto de segunda categoría en T2, se trataría de un impuesto injusto porque la sociedad de la que es socio y en la

${ }^{73}$ Hay quienes podrían sostener que se trata de un impuesto a la riqueza porque los asignatarios deben acumular en el cálculo de la base imponible del impuesto el cúmulo de donaciones que han recibido (art. 23 Ley 16271). Éste es un error. A pesar de que la forma de cálculo del impuesto incluya estas donaciones, no lo transforma en un impuesto a la riqueza porque se sigue gravando el flujo pero esta vez incluye los flujos (las transferencias gratuitas) en el tiempo.

74 Ésta es la forma en que se resuelve un posible problema de doble tributación (a la renta) en nuestro país; i.e. se evita la doble tributación jurídica, que es la doble tributación relevante. De lo contrario, según la definición amplia de renta (renta como incremento patrimonial, conforme a lo establecido en la segunda parte del $\mathrm{N}^{\mathrm{o}} 1$ del art. 2 de la Ley de la Renta), la herencia podría quedar afecta con impuesto a la renta. 
que trabaja ya pagó el impuesto de primera categoría por esa riqueza en T1. Estos ejemplos muestran la importancia de distinguir entre la doble tributación económica (que es irrelevante en los términos en que se discute sobre la doble tributación) y la doble tributación jurídica (que es la que se busca evitar). En el primer ejemplo (el del IVA) hay doble tributación económica en un sentido amplio, pero es irrelevante. En el segundo ejemplo (el del impuesto de primera categoría y el de segunda) no hay doble tributación jurídica. También muestran la importancia de lo que se ha intentado argumentar en este artículo: que los argumentos de justicia requieren contrastar y comparar primeros principios con la regulación institucional. Finalmente, respecto de este argumento, tampoco parece justo extender el concepto de propiedad privada (del causante) a quienes en la familia han ayudado a la creación de la riqueza ${ }^{75}$. ¿Por qué excluir al resto de la sociedad que ha hecho posible esa actividad comercial? ¿Por qué excluir a los empleados que han ayudado al patrón a generar la riqueza?

\section{(c') El impuesto a las herencias no atenta contra las familias}

El argumento (c) es un argumento antojadizo. Para que exista discriminación debe tratarse de un tratamiento moral o jurídico que no pueda justificarse sino que responda al mero arbitrio. La regulación del impuesto a las herencias, como he argumentado en este artículo, responde a una necesidad de justicia y no a un mero tratamiento discriminatorio contra las familias que desarrollan actividades económicas. Este argumento es equivalente a señalar que la tributación que afecta a una sociedad de amigos es discriminatorio contra la amistad. En la vida pública poco importan las motivaciones individuales para formar un negocio o emprender una aventura empresarial. Lo relevante para formar una sociedad comercial es, como sabemos, entre otros requisitos, la affectio societatis, no los vínculos sentimentales o de parentesco. Que una familia decida realizar actividades económicas en nada justifica un tratamiento tributario o legal especial. Tanto la sociedad ("familiar") como sus socios, han dejado de actuar como

${ }^{75}$ Como ya vimos ni siquiera en la teoría de Locke es esta la justificación del derecho a la herencia. 
familia para adoptar relaciones comerciales rigiéndose por los estatutos sociales y la ley comercial ${ }^{76}$. Nuevamente aquí se presenta solapado un argumento de justicia: el hecho de que ciertas familias desarrollen negocios justificaría un tratamiento preferencial especial. Así, se hace evidente la falta de justificación cuando nos preguntamos si para el tipo de sociedad en que queremos vivir es adecuado perpetuar la riqueza dentro de un grupo familiar. Tan clara es la valoración negativa que esto supone que, tal como se ha mostrado en el desarrollo de este trabajo, uno de los fundamentos de la regulación civil de la sucesión como limitación a la libertad de testar del causante es la distribución igualitaria de la riqueza entre los miembros de la familia ${ }^{77}$. Aún más, tampoco parece éste un argumento adecuado para justificar diferencias que generan desigualdades permanentes en nuestras relaciones sociales ${ }^{78}$.

\section{(d') El impuesto a las herencias se aplica de forma inequitativa en} Chile, pero esto no es un argumento para postular su derogación

El cuarto argumento contra el impuesto a las herencias es neutro en términos de principios de justicia. Que se trate de un impuesto que en los hechos se aplica solamente a las familias de "sectores medios y medios bajos" - (por lo que hemos visto aquí el argumento para tener alguna fuerza analítica debería referirse a los asignatarios o a los

${ }^{76}$ Uno de los ejemplos que frecuentemente sirven para argumentar a favor del tratamiento especial que merecerían las familias es que para pagar el impuesto podrían tener que liquidar ciertos bienes. Este caso queda cubierto por las razones de justicia aquí dadas: ¿qué podría arriesgar en términos de justicia la venta de un bien para la justificación del impuesto y de su regulación?

77 Beckert, Inherited Wealth, 2008, capítulos 2 y 3. Y como ya hemos visto este era el argumento de Locke contra la primogenitura. Otros entenderían que existe una discriminación en favor de la familia porque la Ley 16271 establece descuentos en la base imponible que dependen del grado de parentesco (menores mientras más lejano el grado de parentesco). Sin embargo, este tratamiento jurídico es claramente una consecuencia más de la justificación del derecho a la herencia en los términos definidos por Locke, según se explicó antes en este trabajo.

78 Este último es el argumento que llevó a Nozick a revisar su tesis original y terminar proponiendo un impuesto a la herencia como limitación a los efectos de lo que en este trabajo denominé la "potestad de asignar" del titular del derecho de propiedad privada. Véase Nozick, The Examined Life: Philosophical Meditations, 1990, 30-33. 
miembros de la familia en términos individuales y no torcidamente a "las familias") - que no se benefician de las exenciones establecidas en la ley o que a diferencia de las familias con recursos no "planifican la herencia", es una deficiencia de la regulación y no una razón para mostrar que el impuesto es injusto. Por el contrario, si la regulación institucional del impuesto a la herencia es dejada sin efecto por el juego que desarrollan ciertos asesores jurídicos con las normas legales vigentes, es momento de cuestionarnos qué se requiere para asegurar el cumplimiento de las demandas de justicia que justifican la regulación. En otras palabras, que la conducta estratégica de los ciudadanos (hecha posible por sus abogados) esté tradicionalmente arraigada como una cuestión permitida por la forma en que hasta ahora se han interpretado y aplicado las normas tributarias nada dice respecto de la justicia de la institución (a lo más dice algo respecto de la injusticia en la aplicación de las normas jurídicas). Para los efectos de este trabajo baste con decir que la legitimidad del comportamiento estratégico de los ciudadanos para evitar el pago de impuestos es cuestionable. Una vez que dejamos de entender la legitimidad como sinónimo de legalidad — en el sentido más estricto- se abre el espacio para la discusión. Esta es una cuestión que se encuentra ampliamente desarrollada en el derecho comparado y que tarde o temprano deberá desarrollarse en Chile y aplicarse a toda la regulación tributaria ${ }^{79}$.

\section{(e') El impuesto a las herencias vigente en Chile es una institución de justicia}

Finalmente, la crítica que sostiene que el impuesto a la herencia es poco eficiente también puede ser interpretada de acuerdo a los distintos niveles de análisis desarrollados en este trabajo. En primer lugar, que el impuesto recaude pocos ingresos fiscales puede interpretarse como una consecuencia de un problema de regulación. En este sentido, la baja recaudación podría ser producto de la evasión ("elusión" o "planificación") tributaria y por tanto nada dice respecto de la eliminación del impuesto. Pero, en segundo lugar, y aquí hay que ser cuidadosos, la pregunta es cuál es la vara que se usa para medir la eficiencia del impuesto porque el impuesto no puede ser ineficiente per se. La eficiencia

${ }^{79}$ A modo de ejemplo, Avery Jones, Harris, y Oliver (eds.), Comparative Perspectives on Revenue Law. Essays in Honour of John Tiley, 2008. 
o ineficiencia del impuesto a las herencias como criterio de valoración de la regulación, dependerá de la teoría de la justicia desde la que parta el análisis. Veamos por qué. Que una cosa X sea ineficiente quiere decir que su costo es igual o superior al beneficio obtenido. La pregunta entonces, antes de la eficiencia, es sobre el "beneficio" que se persigue con el impuesto a las herencias. Como se ha argumentado extensamente en este artículo, la justificación del impuesto a las herencias no es aumentar la recaudación fiscal, sino que consiste en dar cuenta de y justificar una situación injusta, i.e. la existencia del derecho a la herencia o de la potestad de asignar como parte del derecho de propiedad privada. Por eso, como se trata de un impuesto que no tiene por función actuar como instrumento de recaudación, el juicio de eficiencia estará orientado a determinar si se trata de una manera eficiente de encarnar la idea de justicia que en este artículo se sostiene justifica al impuesto como un second best (y no cuánta recaudación se consiga), i.e. la existencia de un derecho a la herencia o la potestad de asignar como parte del derecho de propiedad privada. Así, conforme al argumento de este artículo, ahora parece evidente que teorías económicas que defienden principios de justicia distintos de los tradicionalmente defendidos por la ortodoxia económica en Chile, lleguen a distintas conclusiones respecto de la eficiencia del impuesto ${ }^{80}$. Como un argumento de justicia, entonces, la eficiencia defendida por aquellos que critican al impuesto es irrelevante una vez que entendemos que, tal como se ha defendido en este artículo, el impuesto a las herencias no tiene como objeto exclusivo ni principal recaudar ingresos para financiar la actividad del Estado, sino que representa una demanda de justicia una vez que entendemos que ésta requiere algún grado de igual reconocimiento.

\section{Conclusión}

Los argumentos esgrimidos contra del impuesto a la herencia en Chile son estériles porque no se condicen con la regulación institucional, o porque a pesar de que puedan tener relación con la regulación chilena sólo muestran la necesidad de mejorar la aplicación de las re-

80 Véase, a modo de ejemplo, Kaplow, The Theory of Taxation and Public Economics, 2008, 36-37 y capítulo 10; los artículos en Erreygers y Vandevelde (eds.), Is Inheritance Legitimate? Ethical and Economic Aspects of Wealth Transfers, 1997; y, Wedgwood, The Economics of Inheritance, 1938. 
glas y no su derogación, o son injustificados porque como defensa de una concepción de justicia contraria a la aquí esbozada como justificación del impuesto (y presente en nuestra regulación civil y tributaria), todavía deben mostrar qué argumentos permitirían calificar que las desigualdades cuyo origen está en la familia (y que el impuesto a las herencias busca eliminar) son justas. De esta forma, según lo argumentado en este artículo, el impuesto a las herencias en Chile está justificado como un second best mientras nuestra legislación incluya en el derecho de propiedad privada la potestad de asignar o reconozca un derecho a la herencia. Así, el impuesto a las herencias deviene en justificación de la propiedad de los herederos por aceptación de los especiales lazos de familia dentro de una comunidad política.

\section{REFERENCIAS}

Actas Comisión de Estudio de la Nueva Constitución, disponibles en www.bcn.cl. Atkinson, A. y J. Stiglitz. Lectures on Public Economics. New York: McGrawHill Book Company, 1980.

Avery Jones, J., P. Harris y D. Oliver (eds.). Comparative Perspectives on Revenue Law. Essays in Honour of John Tiley. Cambridge: Cambridge University Press, 2008.

Batchelder, L. L. "Estate Tax Reforms: Issues and Options". Tax Notes, febrero (2009), pp. 633-647.

- "Taxing Privilege More Effectively: Replacing the Estate Tax with an Inheritance Tax". SSRN eLibrary (2007).

- "What Should Society Expect from Heirs? A Proposal for a Comprehensive Inheritance Tax". Tax Law Review 63, 1 (2009), pp. $1-112$.

Beckert, J. Inherited Wealth. Princeton, N.J., Oxford: Princeton University Press, 2008.

Boadway, R. y D. Wildasin. Public Sector Economics. Boston: Little, Brown and Company, 1984.

Cohen, G. A. Rescuing Justice \& Equality. Cambridge, London: Harvard University Press, 2008.

Dworkin, R. Sovereign Virtue. Cambridge, London: Harvard University Press, 2000.

"El Ladrillo": Bases de la Política Económica del Gobierno Militar Chileno. Santiago de Chile: Centro de Estudios Públicos, 1992.

Erreygers, G. y T. Vandevelde. Is Inheritance Legitimate? Ethical and Economic Aspects of Wealth Transfers. Berlin: Springer-Verlag, 1997.

Evans E. y E. Evans. Los Tributos ante la Constitución. Santiago de Chile: Editorial Jurídica, 1997. 
Fabre, C. "The Choice-Based Right to Bequeath". Analysis 61.1 (enero 2001), pp. 60-65.

—. "Posthumous Rights". En M. Kramer, C. Grant, B. Colburn y A. Hatzistavrou (editores), The Legacy of H. L. A. Hart: Legal, Political, and Moral Philosophy. Oxford: Oxford University Press, 2008, pp. 225-238.

Graetz, M. J., y I. Shapiro. Death by a Thousand Cuts. The Fight over Taxing Inherited Wealth. Princeton, Oxford: Princeton University Press, 2005.

Hohfeld, W. N. Conceptos Jurídicos Fundamentales. Traducción de G. Carrió. México: Fontamara, 1991.

Honoré, T. Making Law Bind: Essays Legal and Philosophical. Oxford: Clarendon Press, 1987.

Kaplow, L. The Theory of Taxation and Public Economics. Princeton y Oxford: Princeton University Press, 2008.

Lehner, M. "The European Experience with a Wealth Tax: A Comparative Discussion". Tax Law Review 53 (1999-2000), pp. 615-691.

Locke, J. y I. Shapiro. Two Treatises of Government; and a Letter Concerning Toleration. Rethinking the Western Tradition. New Haven, London: Yale University Press, 2003.

Mintz, J. "The Role of Wealth Taxation in the Overall Tax System". Canadian Public Policy 17, N 3 (1991), pp. 248-263.

Murphy, L., y T. Nagel. The Myth of Ownership. Taxes and Justice. New York: Oxford, 2001.

Murphy, L. "Institutions and the Demands of Justice". Philosophy \& Public Affairs 27 (1998), pp. 251-291.

- Moral Demands in Nonideal Theory. Oxford: Oxford University Press, 2000.

Musgrave, R., P. Musgrave y R. Bird. Public Finance in Theory and Practice. Toronto: McGraw-Hill, 1987.

Nozick, R. The Examined Life: Philosophical Meditations. New York: Touchstone, 1990.

O'Neill, O. Towards Justice and Virtue: A Constructive Account of Practical Reasoning. Cambridge: Cambridge University Press, 1996.

Räikkä, J. "The Problem of the Second Best: Conceptual Issues". Utilitas 12, $\mathrm{N}^{\circ} 02$ (2001), pp.204-218.

Rakowski, E. “Can Wealth Taxes be Justified?". Tax Law Review 53 (19992000), pp. 263-375.

Rawls, J. Liberalismo Político. Ciudad de México: Fondo de Cultura Económica, 1995.

—. Teoría de la Justicia [1971]. México: Fondo de Cultura Económica, 1995.

- A Theory of Justice [1971]. Cambridge: Belknap Press, 1999.

Rudnik, R. y R. Gordon. "Taxation of Wealth". En V. Thuronyi (ed.), Tax Law Design and Drafting. Part I, Capítulo 10, pp. 292-339. The Hague/ London/Boston: Kluwer Law International, 2000.

Savigny, F. von. Sistema del Derecho Romano Actual. Madrid: F. Góngora y Compañía Editores, 1878. 
Sperling, D. "Posthumous Interests: Legal and Ethical Perspectives". En Cambridge Law, Medicine, and Ethics. Cambridge: Cambridge University Press, 2008.

Steiner, H. An Essay on Rights. Oxford: Blackwell, 1994.

Waldron, J. "Locke's Account of Inheritance and Bequest". Journal of the History of Philosophy 19, $\mathrm{N}^{\circ} 1$ (1981), pp. 39-51.

. The Right to Private Property. Oxford: Oxford University Press, 1988.

_. "Supply without Burthen Revisited". Iowa Law Review 82 (1996), pp. 1467-1485.

Wedgwood, J. The Economics of Inheritance. London: Pelican Books, 1938.

White, S. "What (If Anything) Is Wrong with Inheritance Tax?". The Political Quarterly 79, $\mathrm{N}^{\circ} 2$ (2008), pp. 162-171. 